EESTI NSV TEADUSTE AKADEEMIA TOIMETISED, 22, KOIDE KEEMIA * GEOLOOGIA, 1973, NR. 1

ИЗВЕСТИЯ АКАДЕМИИ НАУК ЭСТОНСКОИ ССР. ТОМ 22 ХИМИЯ * ГЕОЛОГИЯ. 1973, № 1

\title{
ОПРЕДЕЛЕНИЕ ТЕПЛОВОГО ЭФФЕКТА ТЕЛОМЕРИЗАЦИИ ПЕНТАДИЕНА-1,3 С 2-ХЛОРПЕНТЕНОМ-3
}

Теломеризация пентадиена-1,3 с 2-хлорпентеном-3 является промежуточным этапом синтеза разных органических веществ. Образовавшаяся при теломеризации смесь продуктов имеет сложный состав, ее трудно разделить на индивидуальные вещества. Полученный теломер может стать исходным веществом для дальнейшего этапа синтеза и без предварительного разделения его на индивидуальные химические вещества Ввиду этого, единственным способом определения теплового эффекта реакции, необходимого для современного аппаратурного оформления процесса, является его калориметрическое определение.

\section{Методика}

При определении теплового эффекта теломеризации применялась аппаратура, описанная в нашей предыдущей статье [']. Использованные пентадиен-1,3 и 2-хлорпентен-3 очищались перед каждым опытом от продуктов полимеризации дистилляцией. В качестве растворителя употреблялся дихлорэтан, предварительно осушенный на фосфорном ангидриде. Содержание влаги исходных веществ и растворителя, определенное по методу Фишера, не превышало $0,05 \%$. В качестве катализатора использовался $3 \%$-ный раствор безводного хлорного олова в дихлорэтане, для прекращения реакции - высушенный гранулированный карбамид.

В начале опыта в реактор калориметра вливали пентадиен-1,3, 2-хлорпентен-3 и растворитель. Молекулярное соотношение реагирующих компонентов 1:1. Затем калориметрическую систему закрывали и регулировали температуру калориметрического сосуда на $20^{\circ} \mathrm{C}$. После достижения установившегося температурного режима в реактор вводили катализатор. Последний дозировали через резиновую пленку при помощи шприца. При достижении желательной степени превращения, о которой судили по повышению температуры в калориметрическом сосуде, в реактор добавляли карбамид. При каждом опыте калориметр калибрировали электрическим током по эффекту Джоуля.

Реакционную смесь для удаления карбамида отфильтровали через стеклянный фильтр. Количество образовавшегося теломера определялось дистилляцией. Так как дистилляция не позволяет четкого разделения исходных компонентов от теломера, использовались промежуточные фракции, состав которых определялся хроматографически. При расчетах количество теломера, содержащегося в промежуточных фракциях, было добавлено к общему количеству теломера. 


\section{Анализ опытных данных}

Основные данные калориметрических опытов приведены в табл. 1 и на рисунке. Как видно из рисунка, экзотермический тепловой эффект реакции на 1 г образовавшегося теломера с увеличением степени преврашения значительно повышается.

При реакции теломеризации к 2-хлорпентену-3 могут присоединяться одна или несколько молекул пентадиена-1,3. Образующиеся молекулы теломера имеют соответственно 10, 15, 20 и т. д. атомов углерода. Фракции $\mathrm{C}_{10}, \mathrm{C}_{15}$ и $\mathrm{C}_{20}$ трудноразделяемы при помощи обыкновенной дистилляции, и кроме того, теломер может еще разлагаться. Поэтому мы опре-

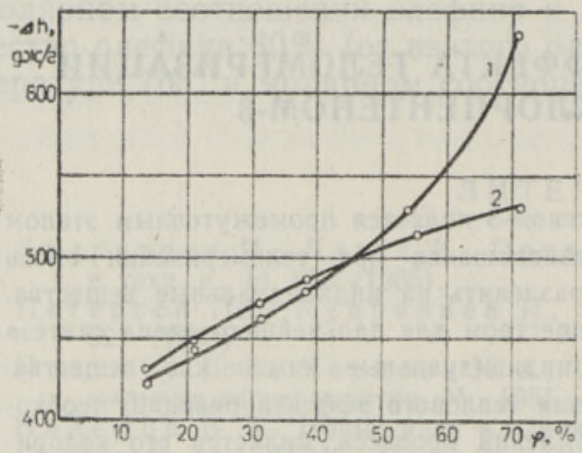

Зависимость теплового эффекта теломеризащии от степени превращения исходных веществ.

1 - экспериментальные данные, 2 расчетные данные.

деляли фракционный состав теломера расчетным путем, а экспериментально измерялись только молекулярный вес теломера и общее содержание хлора в нем.

Сравнение среднего молекулярного веса теломера и общего содержания хлора в последнем показывает, что при теломеризации образуются дихлориды, содержание которых с повышением степени превращения увеличивается. Допуская, что при теломеризации образуются только дихлориды $\mathrm{C}_{10} \mathrm{H}_{18} \mathrm{Cl}_{2}$ и монохлориды $\mathrm{C}_{10}$ и $\mathrm{C}_{15}$, по среднему молекулярному весу и общему содержанию хлора можно рассчитать состав теломера.

При теоретическом расчете теплового эффекта теломеризации можно и не учитывать образование высших монохлоридов $\left(\mathrm{C}_{20}, \mathrm{C}_{25}\right.$ и т. д.), так как теплоты присоединения пентадиена-1,3 к 2-хлорпентену и к аналогичным монохлоридам $\mathrm{C}_{10}, \mathrm{C}_{15}$ и $\mathrm{C}_{20}$ теоретически одинаковы, а количество присоединений характеризуется средним молекулярным весом монохлоридов. Расчетный состав теломера, по которому рассчитан тепловой эффект теломеризации, приведен в табл. 2.

За основу расчета взяты аддитивные вклады структурных единиц [ $\left.{ }^{2}\right]$ и энтальпии образования цис- и транс-пентадиена-1,3 [3]. Причем предполагали следующее: 1) цис- и транс-пентадиен-1,3 реагируют в одинаковых количествах, 2) цис- и транс-расположения в 2-хлорпентен-3 при образовании монохлоридов не изменяется, 3) при присоединении пентадиена-1,3 к хлориду образуется равное количество двойных связей с цис- и транс-расположением, 4) при образовании дихлоридов цис- и транс-2-хлорпентен-3 реагируют равноценно.

Найденные величины тепловых эффектов реакции образования отдельных компонентов теломера $\mathrm{C}_{10} \mathrm{H}_{17} \mathrm{Cl}, \mathrm{C}_{15} \mathrm{H}_{25} \mathrm{Cl}$ и $\mathrm{C}_{10} \mathrm{H}_{18} \mathrm{Cl}_{2}$ из пентадиена-1,3 и 2-хлорпентена-3 составляют соответственно 392, 560 и 358 дж/2. Рассчитанные суммарные тепловые эффекты теломеризации приведены на рисунке.

При степени превращения исходных веществ выше $50 \%$ экспериментально найденные тепловые эффекты значительно превышают расчетные. Это различие не может быть объяснено теплотой растворения, так как 

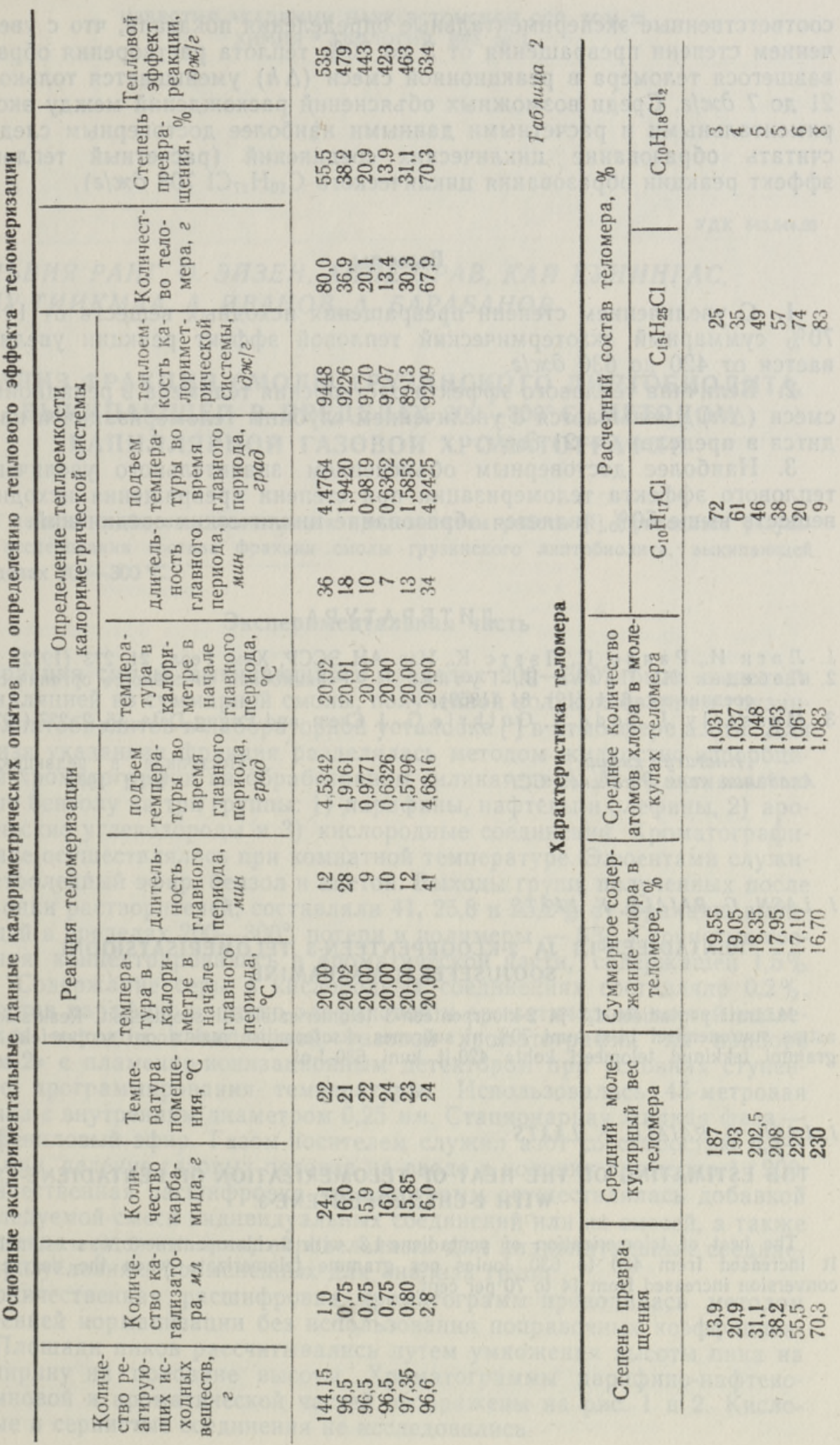

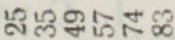

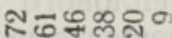

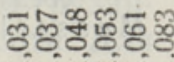

$x$

플 융 \%용 a

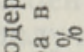

내늉ํㅠ으유

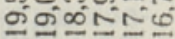

ลิํํำล

สีสีสักี

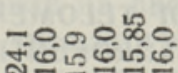

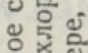

产证

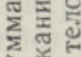

ऊे

๖ં

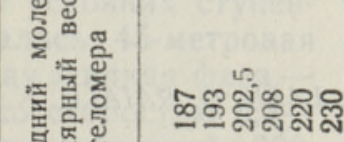

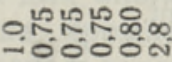

ำน น นิ०

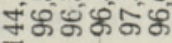

ตำ-ตุเต

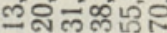


соответственные экспериментальные определения показали, что с увеличением степени превращения от 3 до $70 \%$ теплота растворения образовавшегося теломера в реакционной смеси $(\Delta h)$ уменьшается только от 21 до $7 \partial \varkappa / 2$. Среди возможных объяснений расхождений между экспериментальными и расчетными данными наиболее достоверным следует считать образование циклических соединений (расчетный тепловой эффект реакции образования циклического $\mathrm{C}_{10} \mathrm{H}_{17} \mathrm{Cl} 708$ дж/2).

\section{Выводы}

1. С увеличением степени превращения исходных веществ от 14 до $70 \%$ суммарный экзотермический тепловой эффект реакции увеличивается от 420 до $630 \mathrm{\partial \varkappa /2.}$

2. Величина теплового эффекта растворения теломера в реакционной смеси $(\Delta h)$ уменьшается с увеличением глубины теломеризации и находится в пределах $7-21$ жж/2.

3. Наиболее достоверным объяснением значительного увеличения теплового эффекта теломеризации при степени превращения исходных веществ выше $50 \%$ является образование циклических соединений.

\section{ЛИТЕРАТ У Р А}

1. Л асн И., Раяло Г., Л ээ тс К., Изв. АН ЭССР, Хим. Геол., 21, 273 (1972).

2. Л е бедев Н., Пальм В., Гутнер Н., Реакционная способность органических соединений, 6, 1 (19), 84 (1969).

3. Messerly J., Todd S., Guthrie G., J. Chem. and Engng Data, 15, 2, 227 (1970).

$\begin{array}{cc}\text { Институт химии } & \text { Поступила } \\ \text { Академии наук } \text { встонской ССР } & 2 / \mathrm{III} \\ 1972\end{array}$

J. LASN, G. RAJALO, K. LAATS

\section{PENTADIEEN-1,3 JA 2-KLOORPENTEEN-3 TELOMERISATSIOONI SOOJUSEFEKTI MÄĂRAMINE}

Määrati pentadieen-1,3 ja 2-kloorpenteen-3 telomerisatsiooni soojusefekt. Reaktsiooniastme suurenemisel 14-st kuni $70 \%$-ni suurenes eksotermilise reaktsiooni soojusefekt ühe grammi tekkinud telomeeri kohta 420 -lt kuni $630-\mathrm{J}-\mathrm{ni}$.

\section{J. LASN, G. RAJALO, K. LAATS}

\section{THE ESTIMATING OF THE HEAT OF TELOMERIZATION OF PENTADIENE-1,3 WITH 2-CHLOROPENTENE-3}

The heat of telomerization of pentadiene-1,3 with 2-chloropentene-3 was estimated. It increased from 420 to 630 Joules per gramme telomerizate when the degree of conversion increased from 14 to 70 per cent. 